\title{
Design of Ultrasonic-assisted Microinjection Mold and Cavity Pressure Measurement System
}

\author{
Rongchuan Lin, ${ }^{1}$ Yifan Yin, ${ }^{2}$ Junrong Chen, ${ }^{1}$ and Shasha Wei ${ }^{1 *}$ \\ ${ }^{1}$ School of Mechanical and Energy Engineering, Jimei University, Xiamen, Fujian 361021, China \\ ${ }^{2}$ Xiamen Songlin Technology Co., Ltd., Xiamen, Fujian 361026, China
}

(Received May 31, 2019; accepted September 13, 2019)

Keywords: ultrasonic microinjection, numerical simulation, mold design, pressure sensor, signal acquisition system

On the basis of the characteristics of thin-wall injection molding technology and the principle of ultrasonic vibration, an ultrasonic-assistant system consisting of an ultrasonic generator, an ultrasonic horn, and an ultrasonic transducer is developed in this study. A simulation analysis of the injection molding of thin-wall microinjection parts is conducted using MOLDFLOW to optimize the gate, runner, primary runner, and cooling system of the mold. A cavity pressure measurement system is built for ultrasonic-assisted microinjection molding process pressure detection, the optimization of process parameters, and the improvement of product quality. The development and processing of the ultrasonic-assistant thin-wall microinjection mold are also completed by combining the ultrasonic system, thin-wall microinjection mold, and cavity pressure measurement system.

\section{Introduction}

Owing to the complex manufacturing process, the structure and accuracy requirements of microinjection parts are different from traditional ones. The microinjection parts usually have a fine local structure or a small cavity and therefore have higher requirements for the mold design. At the same time, owing to the small size of microinjection parts, the large surface area of the cavity, and the microscale effect, defects such as inadequate filling, serious warping, large shrinkage, and cavitation often occur, which definitely affect the quality and accuracy of microinjection parts. ${ }^{(1)}$ Compared with conventional microinjection molding methods, the ultrasound-assisted microinjection molding could, on the one hand, reduce the viscosity of the polymer melt to enhance liquidity and improve the internal microstructure and the mechanical properties of products. On the other hand, the appearance quality of products could be improved by reducing the warpage and the plastification quality of the polymer melt could also be improved. ${ }^{(2)}$

Cavity pressure is a practical process parameter of plastic injection molding, which directly affects the quality of products. The technology for sensing the cavity pressure is a method of 
recording and analyzing the actual changes of the melt in the injection process by measuring the pressure of the polymer melt in the mold cavity. The injection start time, V/P switching time, holding time, and cooling time are observed by installing a high-temperature pressure sensor at a reasonable measuring position, so as to record the complete injection cycle and forming process information. It provides real and detailed process information for studying the relationship between injection process and quality, and provides an effective theoretical basis for the scientific adjustment of process parameters. ${ }^{(3)}$

At present, the ultrasonic-assisted injection molds developed by Jiang et al. ${ }^{(4)}$ and Zhang and Gilchrist ${ }^{(5)}$ could install an ultrasonic transducer on the exterior walls of molds or apply ultrasonic vibration at the position of an ejector or the pulling rod of molds, or apply an ultrasonic horn to a cavity. By utilizing the energy generated by ultrasonic vibration, the low temperature at the flow front could be increased to improve its liquidity and filling performance, and the quality of injection products could be improved. In this study, thin-wall parts of modified glass-fiber-reinforced polybutylene terephthalate (PBT) are used to design an integrated ultrasonic vibrator with a transducer and a horn, and an ultrasonic-assisted thin-wall injection molding system is developed. The mold is of single cavity. To ensure the sealing between the vibration head and the cavity, mold inserts for top-down special design structures and fluororubber O-Ring with high-temperature resistance are adopted in the sealing installation of an ultrasound vibration head. In addition, MOLDFLOW is used to analyze the flow pattern to assist the design of the runner and cooling systems to select the best scheme. Finally, the ultrasonic system was combined with a thin-wall microinjection mold and a mold cavity pressure measurement system to complete the development of the ultrasonic-assisted thin-wall microinjection mold and the design of the mold cavity pressure measurement system, optimize process parameters, and improve the product quality.

\section{Design and Installation of Ultrasonic-assisted System}

\subsection{Design of ultrasonic-assisted system}

The ultrasonic-assisted system consists of an ultrasonic generator, an ultrasonic transducer, and an ultrasonic horn. The ultrasonic generator used in this work is an analog signal generator whose working frequency ranges from 20 to $50 \mathrm{kHz}$, and could be continuously adjusted in a certain range. The ultrasonic transducer adopts the piezoelectric ceramic transducer. The material type of the piezoelectric ceramic sheet is PZT8, the intermediate electrode material is beryllium copper, and the bolt steel whose tensile strength is above $80 \mathrm{~kg} / \mathrm{mm}$ is used for the screw. The ultrasonic horn is a stepped horn with arc transition. To fit the cavity surface well, a $\varphi 5 \mathrm{~mm}$ mutation end is designed at the front end of the horn. On the other hand, for processing and assembling convenience, an integrated structure of the ultrasonic vibrator is adopted in this experiment, that is, the transducer and ultrasonic vibrator are integrated. The ultrasonic vibrator is made of aviation aluminum 6061, whose performance parameters are shown in Table $1 .{ }^{(6,7)}$ The 3D model of the ultrasonic vibrator is shown in Fig. 1. The picture of the ultrasonic vibrator used in this study is shown in Fig. 2. 
Table 1

Performance parameters of aviation aluminum 6061.

\begin{tabular}{lc}
\hline Performance index & Parameter value \\
\hline Density $\left(20^{\circ} \mathrm{C}\right) \mathrm{g} / \mathrm{cm}^{3}$ & 2.73 \\
Thermal expansion coefficient $\left(20-100^{\circ} \mathrm{C}\right) \mu \mathrm{m} / \mathrm{m} \cdot \mathrm{k}$ & 23.6 \\
Melting range $\left({ }^{\circ} \mathrm{C}\right)$ & $580-650$ \\
Conductivity $20^{\circ} \mathrm{C}\left(68{ }^{\circ} \mathrm{F}\right)(\% \mathrm{IACS})$ & 43 \\
Resistivity $20^{\circ} \mathrm{C}\left(68^{\circ} \mathrm{F}\right) \Omega \mathrm{mm}^{2} / \mathrm{m}$ & 0.040 \\
Tensile strength $\left(25^{\circ} \mathrm{C} \mathrm{MPa}\right)$ & 310 \\
Yield strength $\left(25^{\circ} \mathrm{C} \mathrm{MPa}\right)$ & 276 \\
\hline
\end{tabular}

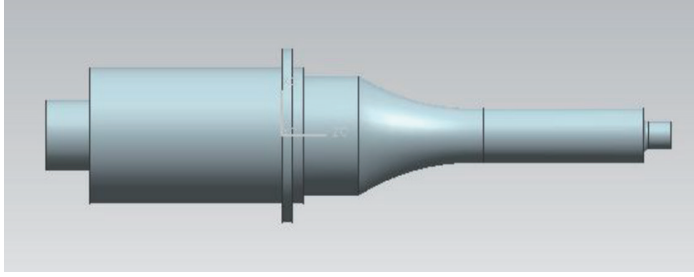

Fig. 1. (Color online) 3D model of ultrasonic vibrator.

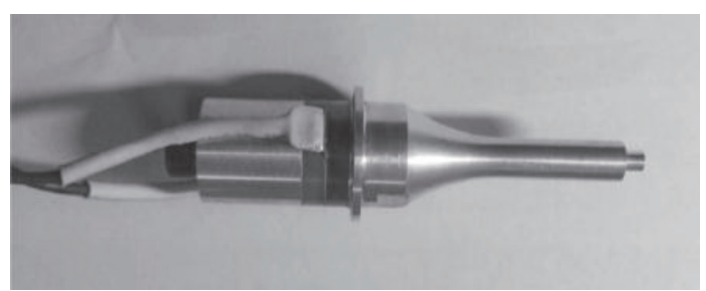

Fig. 2. Picture of ultrasonic vibrator.

\subsection{Installation of ultrasonic-assisted system}

In this study, the elastic-element-assisted locking method is used. That is, a small disc at the displacement node of the ultrasonic oscillator is tightened by a compression block and an epoxy resin gasket, and then the small disc and flange are locked by screws. The installation diagram is shown in Fig. 3. Such a method could effectively reduce not only the loss of sound energy and the internal stress of flange to prolong the service life, but also the heat transfer in the mold, so as to ensure that the ultrasonic vibrator can work normally at a suitable temperature and avoid the damage of the ultrasonic vibration system due to overheating.

\section{Design of Cavity Pressure Measuring System}

The pressure sensor selected in this study is a KISTLER 6157B cavity pressure sensor, with an end face diameter of $4 \mathrm{~mm}$ and a pressure range as high as 2000 bar. The pressure sensor is installed at the gate position to collect the cavity pressure. After the pressure sensor measures the pressure signal, it is converted into an analog signal through $\mathrm{A} / \mathrm{D}$, and the collected data is appropriately amplified through the signal amplifier and input into each module of the software system. After the pressure signal is obtained by the software system, noise reduction processing such as linear fitting is carried out. Analyse and record the data and key points of each cycle process, and then obtain the corresponding $\mathrm{Cp} / \mathrm{Cpk}$ and other statistical values. These statistics are output to the display panel as curve optimization data to allow injection personnel to check the change in pressure in the cavity. 


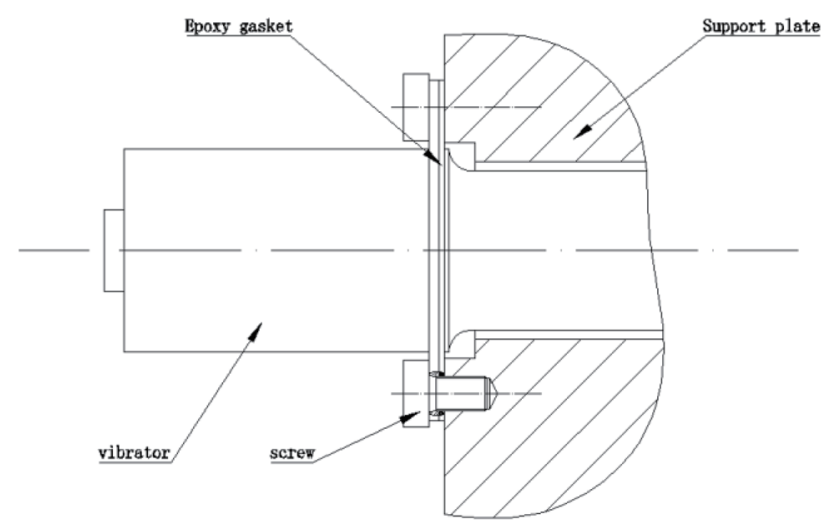

Fig. 3. Diagram of installation of ultrasonic vibrator.

\section{Design of Ultrasonic-assisted Microinjection Mold}

The products used in this study are the 0.3 -mm-thick thin-wall parts made of modified glassfiber-reinforced PBT. The outline dimension figures are shown in Fig. 4.

\subsection{Design of the runner system of the ultrasonic-assisted thin-wall injection mold based on MOLDFLOW}

The gating system refers to the plastic flow path from the injector nozzle to the cavity entrance, which is divided into cold and hot runners, and consists of a primary runner, a subrunner, a gate, and a cool material cave. ${ }^{(8,9)}$ To effectively test the effect of the ultrasonicassist system, the conventional cold runner system is adopted in this study.

\subsubsection{Gate design}

The gate is the delivery channel connecting the subrunner and the cavity of the mold. ${ }^{(6)}$ At present, the main types of gate used in production are edge gate, pin gate, submarine gate, fan gate, cashew gate, and so forth. A fan gate is defined as a gate whose width increases gradually in the length direction while its thickness decreases gradually and it shows a fan shape. The fan gate is often used to form flat and thin plastic parts, and its usage is conducive to a more uniform and stable filling flow of high-temperature polymer melt in the width direction, thus reducing the stress of plastic parts, effectively avoiding the adverse effects caused by flow liners and directional effects, and reducing the possibility of air entrainment. The thin-wall parts used in this study are $0.3 \mathrm{~mm}$ thick so the fan gate is appropriate for filling.

Three sets of gate schemes, which are shown in Fig. 5 and Table 2 are customized in the paper. We import them into the software MOLDFLOW for grid processing, ${ }^{(10,11)}$ and then set the injection time at $0.5 \mathrm{~s}$ in MOLDFLOW to control the filling analysis. Other forming parameters are process parameters recommended by the MOLDFLOW material library, and the qualities of the parts of the three schemes when a short shot occurs are compared. 


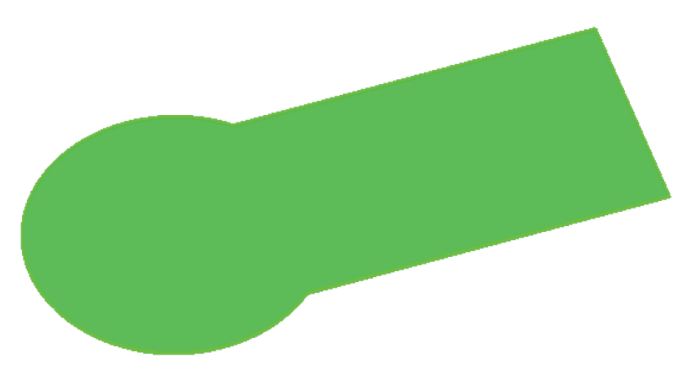

$\begin{array}{rrr}X & -75 \\ 143 \\ -66\end{array}$

Fig. 4. (Color online) Product outline drawing.
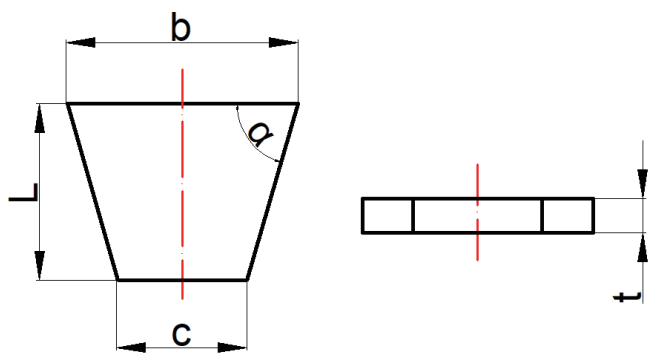

Table 2

Comparison of gas schemes.

\begin{tabular}{lccc}
\hline \multirow{2}{*}{ Parameters } & \multicolumn{3}{c}{ Schemes } \\
\cline { 2 - 4 } & 1 & 2 & 3 \\
\hline$b(\mathrm{~mm})$ & 4 & 5 & 6 \\
$L(\mathrm{~mm})$ & 2.5 & 3 & 3.5 \\
$t(\mathrm{~mm})$ & 0.4 & 0.45 & 0.5 \\
$a(\mathrm{deg})$ & 60 & 60 & 60 \\
$c(\mathrm{~mm})$ & 1.6 & 1.8 & 2 \\
\hline
\end{tabular}

Fig. 5. (Color online) Dimensional parameter diagram of fan gate.

The filling analysis results of schemes 1, 2, and 3 are shown in Fig. 6. According to the log of the filling analysis results, the following conclusions can be drawn:

In scheme 1, short shots occur when the filling time reaches $0.2993 \mathrm{~s}$. The percentage of filling volume is $42.21 \%$ and the quality of parts is $0.5668 \mathrm{~g}$. In scheme 2 , short shots occur when the filling time reaches $0.2889 \mathrm{~s}$. The percentage of filling volume is $42.09 \%$ and the quality of parts is $0.5717 \mathrm{~g}$. In scheme 3 , short shots occur when the filling time reaches $0.2963 \mathrm{~s}$. The percentage of filling volume is $42.44 \%$ and the quality of parts is $0.5693 \mathrm{~g}$. The analysis data of the three schemes are arranged and plotted in Fig. 7, from which it can be directly seen that scheme 2 is the best one.

\subsubsection{Subrunner design}

The subrunner refers to the runner between the end of the primary runner and the gate. The flow resistance of the melt should be kept as small as possible in the design of the subrunner. The section shapes of the subrunner used in production are usually round, U-shape, semicircle, trapezoid, and rectangle. ${ }^{(12)}$ The trapezoidal and U-shaped sections should only be manufactured on one side of the parting surface, and therefore, are relatively easy to manufacture. Owing to the subtle heat and pressure losses, they are the most commonly used subrunners in production. Finally, the U-shaped runner is selected according to the dimensions 


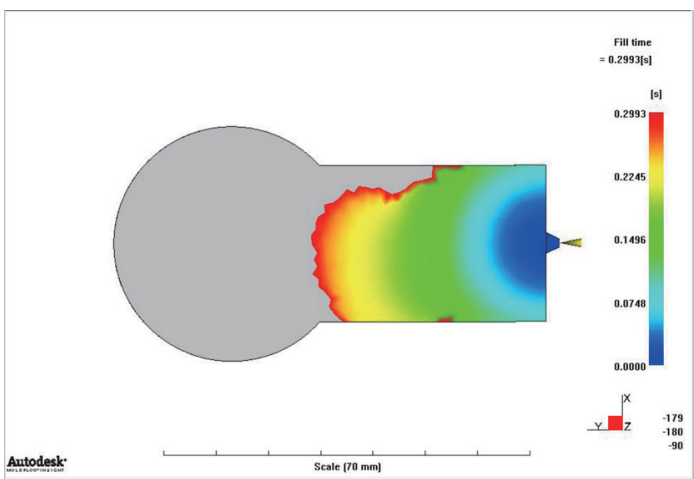

(a)

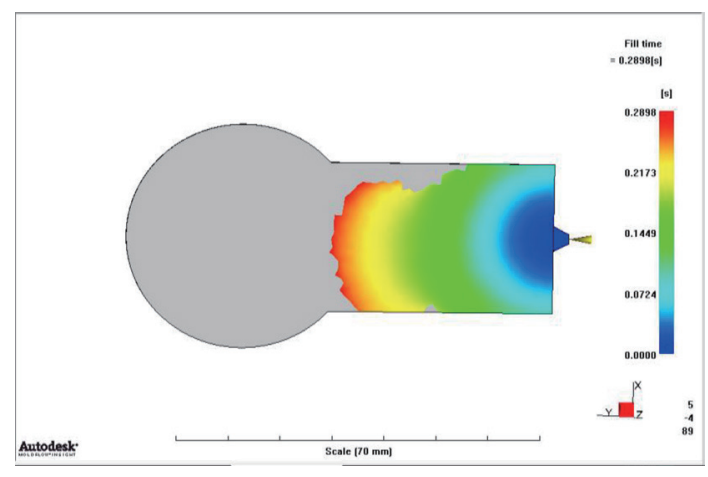

(b)

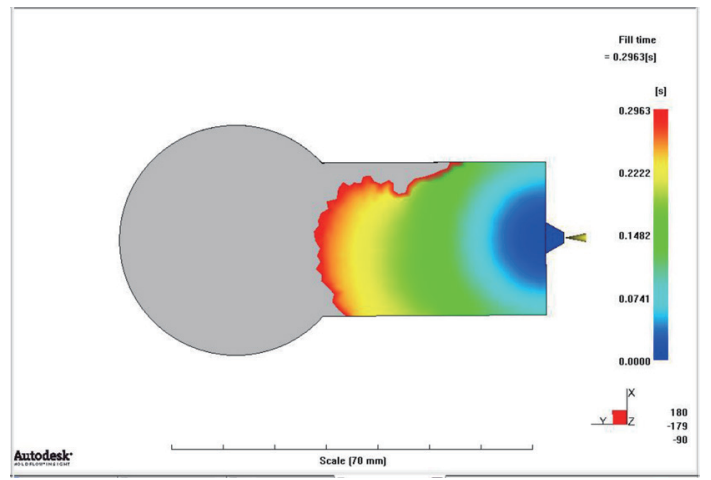

(c)

Fig. 6. (Color online) Filling analysis results of fan gate schemes (a) 1, (b) 2, and (c) 3 .

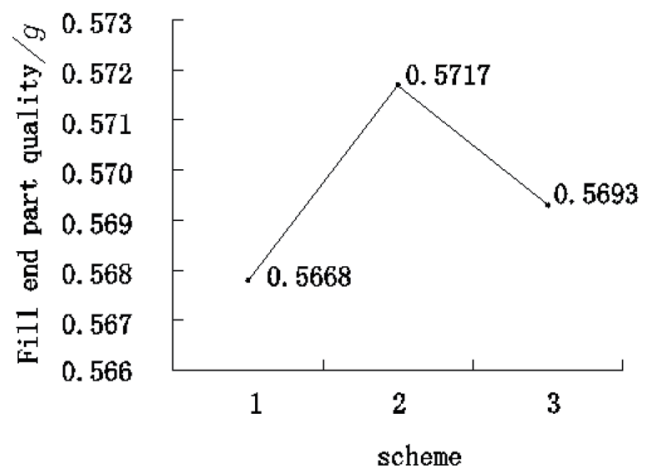

Fig. 7. Contrast curves of filling analysis results for gate design.

of the product combined with the production experience and processing factors of thin-wall parts.

According to the determined runner parameters combined with the size, shape, and longterm mold design experience, three sets of subrunner schemes are customized in this study and shown in Table 3 and Fig. 8. We set the injection time at $0.5 \mathrm{~s}$ in MOLDFLOW to control the filling analysis. The qualities of parts of the three schemes when a short shot occurs are compared to find the best scheme.

The filling analysis results of schemes 1, 2, and 3 are shown in Fig. 9. According to the log of filling analysis results, the following conclusions can be drawn: 
Table 3

Comparison of U-shaped runner schemes.

\begin{tabular}{lccc}
\hline \multirow{2}{*}{ Parameters } & \multicolumn{3}{c}{ Schemes } \\
\cline { 2 - 4 } & 1 & 2 & 3 \\
\hline $\mathrm{a} / \mathrm{mm}$ & 4 & 4.5 & 5 \\
$\mathrm{~b} / \mathrm{mm}$ & 2.2 & 2.5 & 2.8 \\
$\mathrm{~L} / \mathrm{mm}$ & 13 & 13 & 13 \\
\hline
\end{tabular}
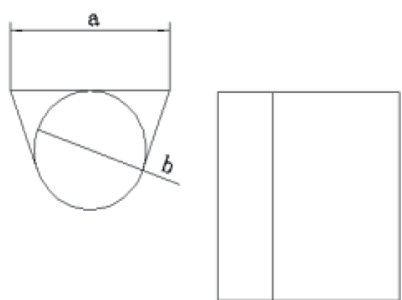

Fig. 8. Dimensional parameter diagram of U-shaped runner.

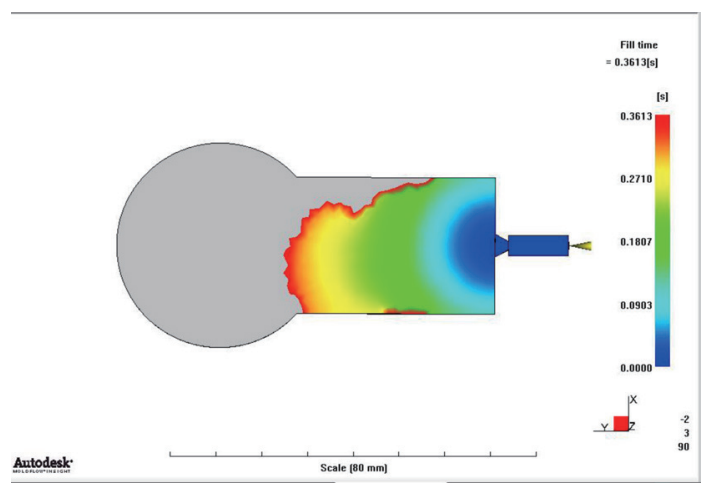

(b)

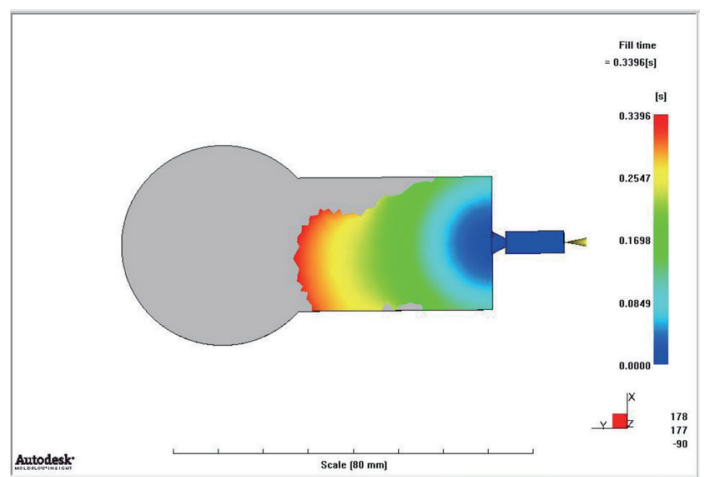

(c)

Fig. 9. (Color online) Filling analysis results of U-shaped runner design schemes (a) 1, (b) 2, and (c) 3 .

In scheme 1, short shots occur when the filling time reaches $0.3498 \mathrm{~s}$. The percentage of filling volume is $42.24 \%$ and the quality of the parts is $0.5664 \mathrm{~g}$. In scheme 2 , short shots occur when the filling time reaches $0.3613 \mathrm{~s}$. The percentage of filling volume is $41.86 \%$ and the quality of parts is $0.5621 \mathrm{~g}$. In scheme 3 , short shots occur when the filling time reaches $0.3449 \mathrm{~s}$. The percentage of filling volume is $41.12 \%$ and the quality of parts is $0.5593 \mathrm{~g}$. The analysis results of the three schemes are arranged and plotted in Fig. 10, from which it can be directly seen that scheme 1 is the best one. 


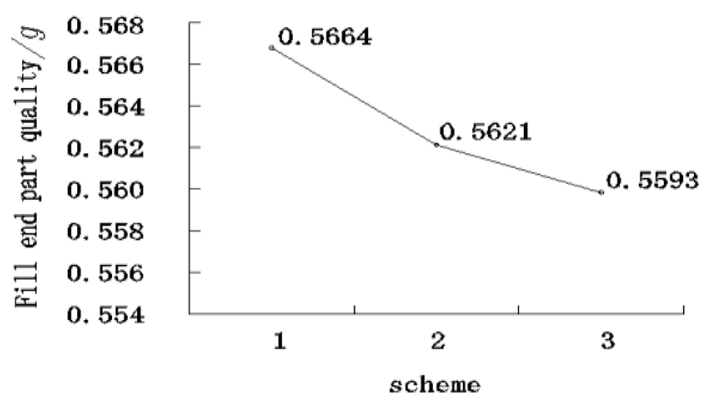

Fig. 10. Contrast curve of filling analysis results for U-shaped runner design.

\subsubsection{Primary runner determination}

The primary runner is defined as the flow channel of high-temperature polymer melts from the contact position between the injection nozzle and the gate to the end point of the subrunner. ${ }^{(8,9)}$ It is the structure that the plastic melt first flows through in the mold after being heated and plasticized. Its shape and size considerably affect the fluidity and filling property of the hightemperature polymer melt. The primary runner parameters are determined, and three primary runner schemes are customized according to the product size, shape, long-term mold design experience, and MISUMI standard parts. The dimension parameters of the primary runner are shown in Fig. 11 and the comparison of the primary runner schemes is shown in Table 4. We set the injection time at $0.5 \mathrm{~s}$ in MOLDFLOW to control the filling analysis, which is carried out by the conventional injection process for general products. The qualities of parts of the three schemes when a short shot occurs are compared to find the best scheme.

The filling analysis results of schemes 1,2, and 3 are shown in Fig. 12. According to the log of filling analysis results, the following conclusions can be drawn:

In scheme 1 , short shots occur when the filling time reaches $0.3649 \mathrm{~s}$. The percentage of filling volume is $37.34 \%$ and the quality of parts is $0.5100 \mathrm{~g}$. In scheme 2 , short shots occur when the filling time reaches $0.1726 \mathrm{~s}$. The percentage of the filling volume is $15.36 \%$ and the quality of parts is $0.2047 \mathrm{~g}$. In scheme 3 , short shots occur when the filling time reaches $0.3904 \mathrm{~s}$. The percentage of filling volume is $39.20 \%$ and the quality of parts is $0.5274 \mathrm{~g}$. The analysis results of the three schemes are arranged and plotted in Fig. 13 from which it can be directly seen that scheme 3 is the best one.

\subsection{Design of ultrasonic-assisted mold cooling system based on MOLDFLOW}

In microinjection molding, the temperature of the mold has a direct impact on the molding quality and production efficiency of the plastic parts. ${ }^{(13,14)}$ The temperature-regulating system of the mold is also called the mode-cooling system. It is very important for the quality of molded products to design a reasonable cooling system and realize the effective adjustment of the mold temperature. Three cooling systems are designed in this study, which are shown in 

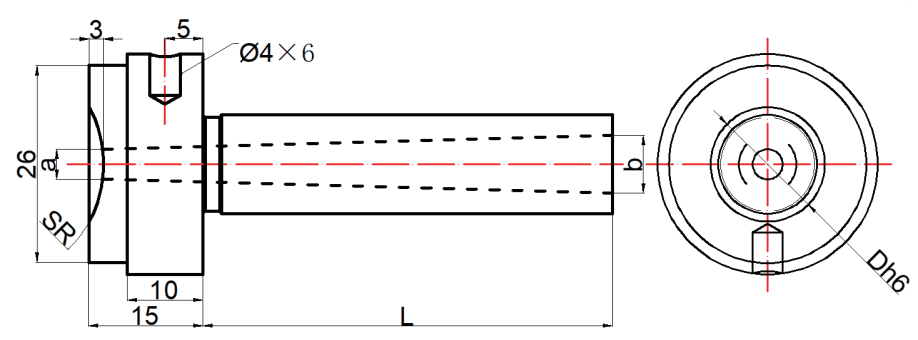

Table 4

Comparison of primary runner schemes.

\begin{tabular}{llll}
\hline \multirow{2}{*}{ Parameters } & \multicolumn{3}{c}{ Schemes } \\
\cline { 2 - 4 } & 1 & 2 & 3 \\
\hline$a$ & 2 & 2.5 & 2 \\
$b$ & 5.2 & 5.8 & 4.8 \\
$S R$ & 11 & 11 & 11 \\
So & 53.5 & 53.5 & 53.5 \\
$D h 6$ & 12 & 12 & 12 \\
\hline
\end{tabular}

Fig. 11. (Color online) Primary runner dimension parameter diagram.

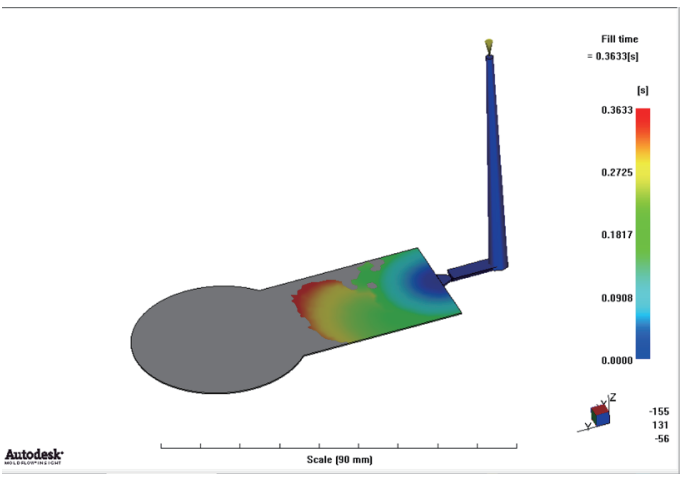

(a)

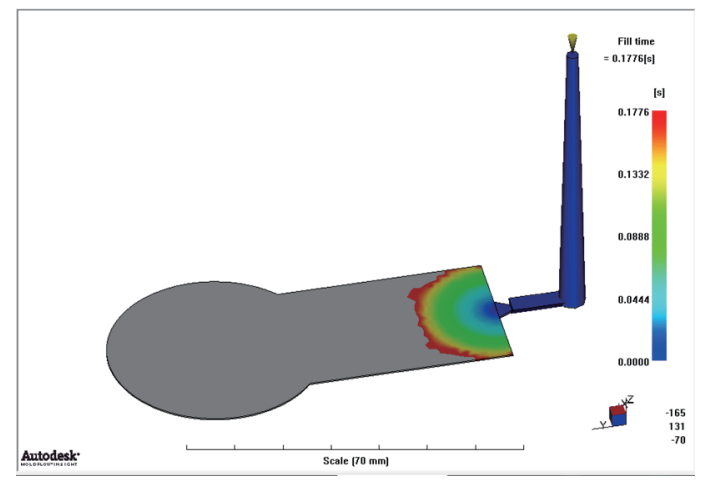

(b)

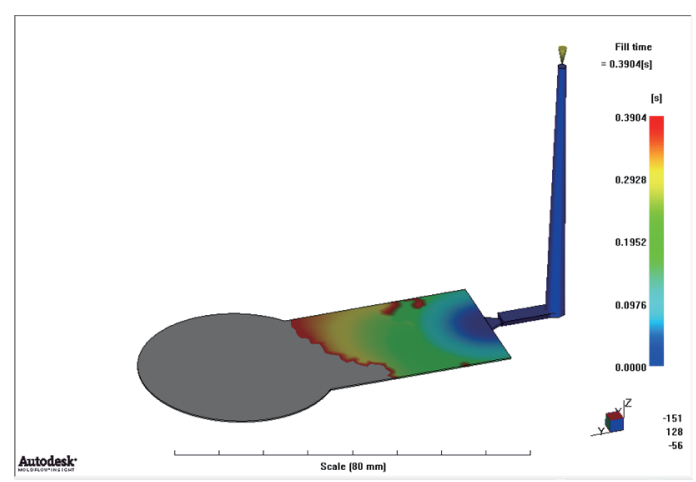

(c)

Fig. 12. (Color online) Filling analysis results of main channel design schemes (a) 1, (b) 2, and (c) 3 .

Fig. 14 and Table 5. The 3D model is drawn by UG and then imported into MOLDFLOW for grid processing. With the injection time of $0.6 \mathrm{~s}$, the melt temperature of $320^{\circ} \mathrm{C}$, and the coolant temperature of $80{ }^{\circ} \mathrm{C}$, filling and cooling analyses are carried out. The cooling parameters of the parts after filling are compared and analyzed, and finally, the cooling schemes are determined.

Through the simulation analysis of MOLDFLOW on filling and cooling, the temperature distributions of the three schemes with different paths are obtained in Fig. 15 at five locations, namely, N10819, N10611, N10385, N10419, and N10367 (shown in Fig. 16). 


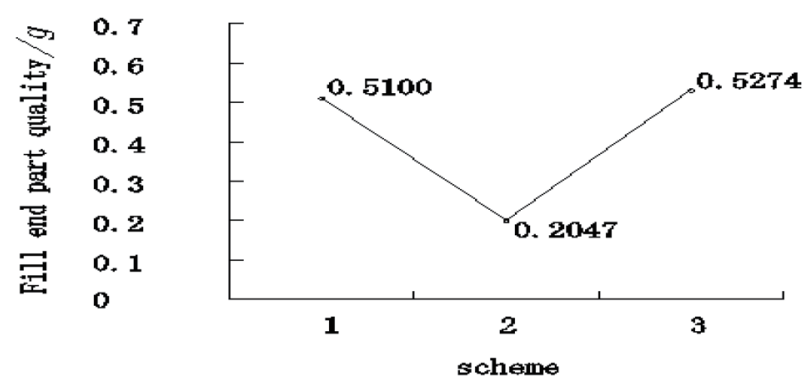

Fig. 13. Contrast curve of filling analysis results for primary runner design.

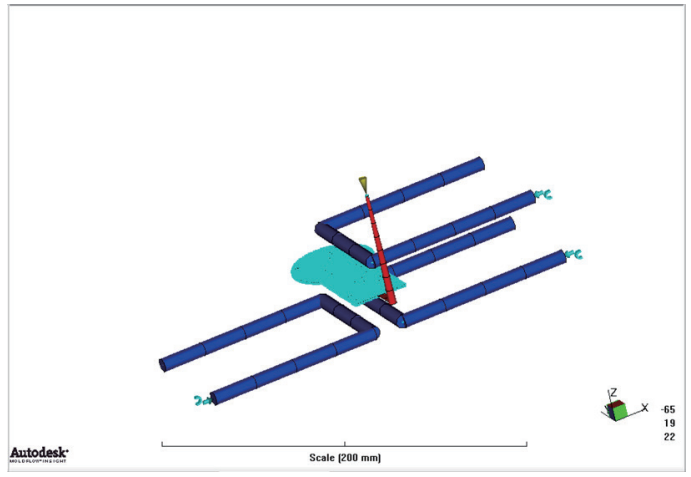

(a)

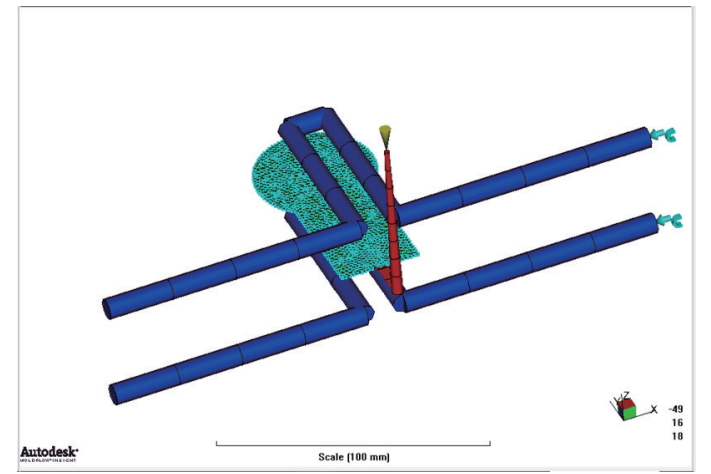

(b)

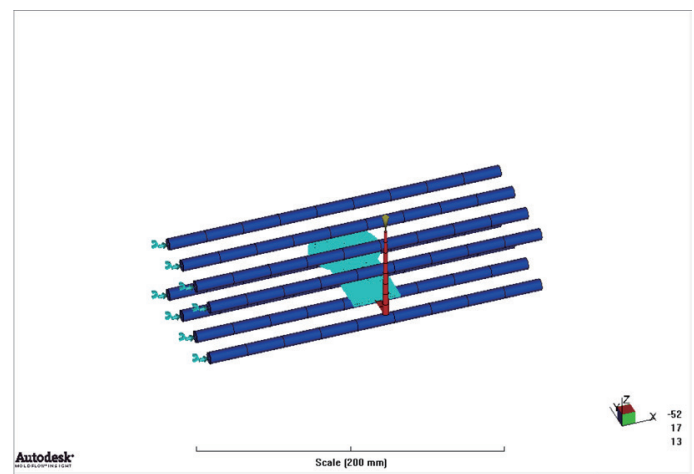

(c)

Fig. 14. (Color online) Cooling loop schemes (a) 1, (b) 2, and (c) 3.

Table 5

Comparison of cooling loop schemes.

\begin{tabular}{lccc}
\hline Position & \multicolumn{3}{c}{ Schemes } \\
\cline { 2 - 4 } & 1 & 2 & 3 \\
\hline Front mold & Intermediate straight line & U-shaped & Throughout straight line \\
Rear mold & Bilateral straight line & U-shaped & Throughout straight line \\
\hline
\end{tabular}

According to the temperature distributions obtained along the paths of the three schemes, the temperature distribution of scheme 2 is the most balanced, and there is no sudden decrease in temperature. The temperature change of scheme 3 is slightly different from that of scheme 2 . The temperature distribution curves of scheme 1 have a large temperature change. Therefore, the cooling loop scheme 2 has the best effect. 


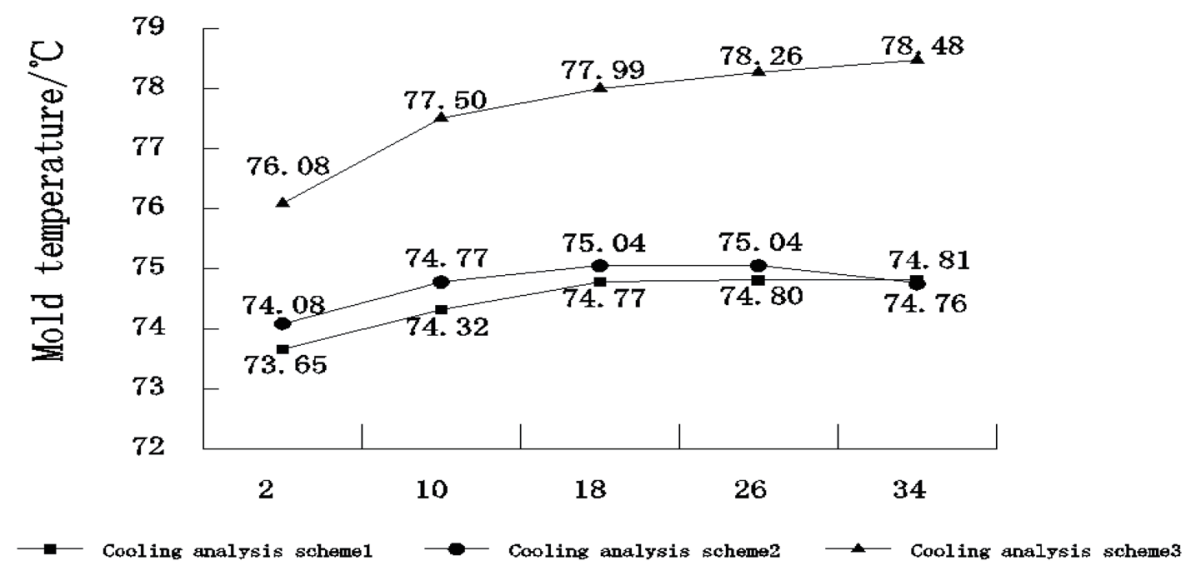

Fig. 15. Contrast curve of temperature distribution along the path.

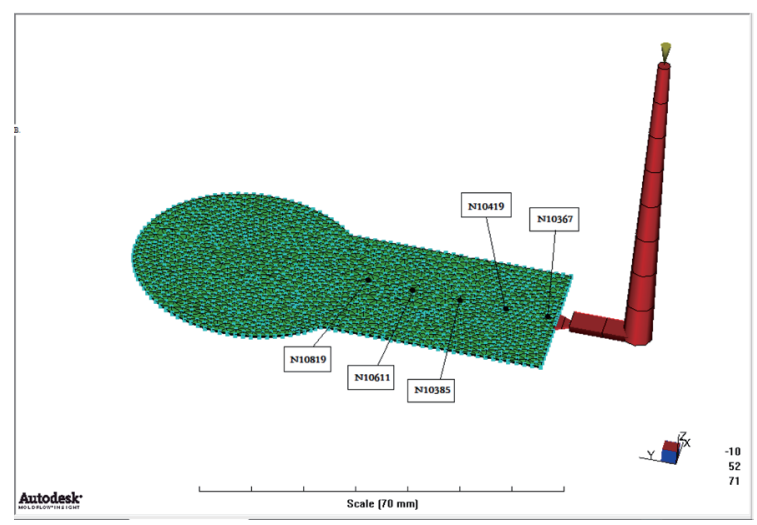

Fig. 16. (Color online) Five-point position map for temperature testing of mold.

There are two main indicators that can be used to measure the performance of the cooling loop of the mold, namely, the shortest cooling time of the product and the best cooling effect of the product on the premise of uniform cooling. After the cooling water enters the cooling pipe from the inlet, the heat of the mold is absorbed, which gradually increases the water temperature. Therefore, there will be a temperature difference between the inlet and the outlet. However, the smaller the temperature difference, the better. A huge temperature difference will lead to uneven cooling on the surface of the mold and easily cause the warpage of the plastic parts. ${ }^{(15-19)}$ Therefore, in this experiment, the indexes used to select the best cooling loop scheme are as follows: the shortest time to reach the ejection temperature, the smallest difference between the maximum and minimum surface temperatures of the parts after cooling, and the lowest maximum temperature of the pipe wall of the loop. The relevant measurement parameters of the three cooling loop schemes are shown in Table 6.

The time to reach the ejection temperature, the difference between the maximum and minimum temperatures at cooling ends, and the difference between the wall temperatures of the loop pipes in the three schemes in Table 6 are respectively plotted in a column diagram in Figs. 17-19. 
Table 6

Analysis results of cooling circuit measurement parameters.

\begin{tabular}{llcc}
\hline \multirow{2}{*}{ Parameters } & \multicolumn{3}{c}{ Schemes } \\
\cline { 2 - 4 } & 1 & 2 & 3 \\
\hline Time to reach ejection temperature, $t(\mathrm{~s})$ & 0.0741 & 0.0742 & 0.0751 \\
Maximum temperature of parts at cooling end, $T_{h}\left({ }^{\circ} \mathrm{C}\right)$ & 99.17 & 99.77 & 103 \\
Minimum temperature of parts at cooling end, $T_{l}\left({ }^{\circ} \mathrm{C}\right)$ & 72.38 & 72.62 & 76 \\
Maximum temperature of loop wall, $T_{0}\left({ }^{\circ} \mathrm{C}\right)$ & 76.61 & 76.10 & 78.26 \\
Minimum temperature of loop wall, $T_{0}\left({ }^{\circ} \mathrm{C}\right)$ & 71.88 & 71.25 & 75.50 \\
\hline
\end{tabular}

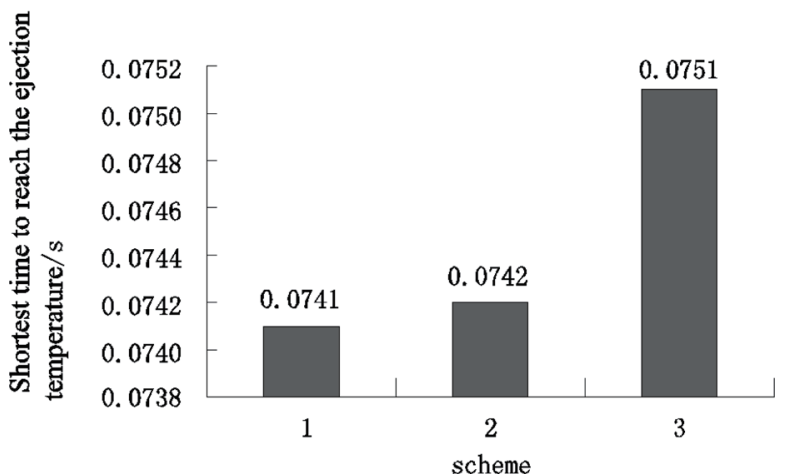

Fig. 17. Contrast column diagram of time result of ejection temperature.

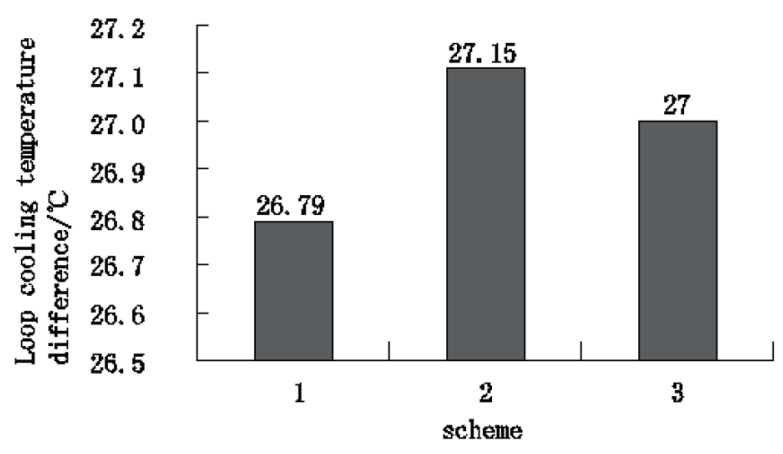

Fig. 18. Cylindrical diagram for comparison of coolant temperature differences.

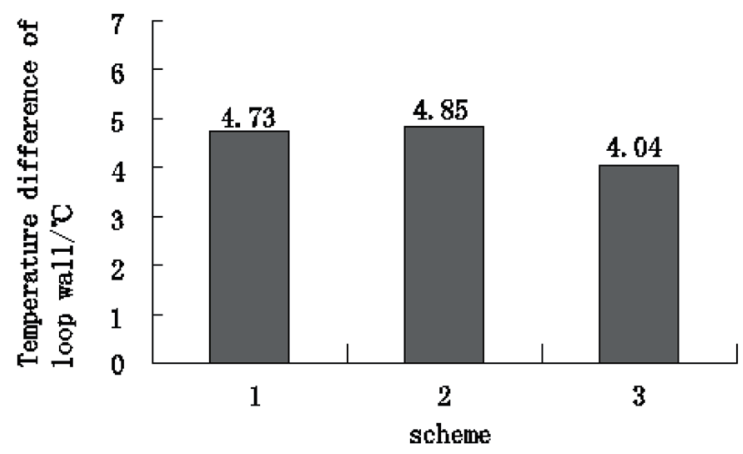

Fig. 19. Contrast column diagram of wall temperature difference of loop pipe.

The cooling analysis results of the three schemes are synthetically analyzed, and scheme 2 is the best. The constant temperature of the cavity will considerably affect the surface quality, filling property, shrinkage after forming, and injection cycle. An excessively high or low temperature of injection molds will have different effects on different materials. This factor is more important than others, so scheme 2 is first listed as the best one. In terms of the temperature of the coolant in the comparative loop, the difference between the three schemes is not large, so this factor can be omitted. Moreover, for the wall temperature of the loop pipe, the best result is that the lower the temperature difference, the better the cooling effect. The optimum value is used to control the temperature within $5{ }^{\circ} \mathrm{C}$, according to MOLDFLOW. All 
three schemes meet the requirements. As for the time to reach the ejection temperature, it could be seen that the three factors are all controlled at about $0.075 \mathrm{~s}$, and the difference is small, so this factor can also be excluded. Therefore, scheme 2 is finally determined to be the optimal scheme, and the final cooling system design is carried out in accordance with scheme 2 .

\subsection{Overall structure design of mold}

According to their structural characteristics, injection molds could be divided into two-plate, three-plate, and injection molds with movable inserts, side parting, and core pulling. ${ }^{(8,9)}$

Because only flat parts with simple structures are used in this study, the two-plate mold is adopted. According to the overall size of the plastic parts and the strength and stiffness requirements, considering the integration of the thin-wall injection mold and ultrasonic-assisted vibration system, and the maximum opening stroke of the injection machine, the $25 \times 35$ AI-standard mold base of LUNG KEE GROUP (LKM) is selected. The A plate thickness is $70 \mathrm{~mm}$, the B plate thickness is $60 \mathrm{~mm}$, and the C plate thickness is $80 \mathrm{~mm}$. The overall size is $350 \times 300 \times 276 \mathrm{~mm}^{3}$.

Considering the product size, cavity layout, and ejector guide pin spacing, and considering the installation of the ultrasonic-assisted system in the experiment, the single cavity mold layout is selected. At the same time, to facilitate remolding and ensure that the plastic parts remain on the side of the moving mold when opening, the parting surface is selected on the upper surface of the plastic parts. According to the design of the gating and cooling systems based on MOLDFLOW, as well as the design of standard parts of general molds, the 3D model is built by UG. Then, it is processed and manufactured. The structure diagram of the key parts of the mold is shown in Fig. 20(a) and the picture of the thin wall is shown in Fig. 20(b).

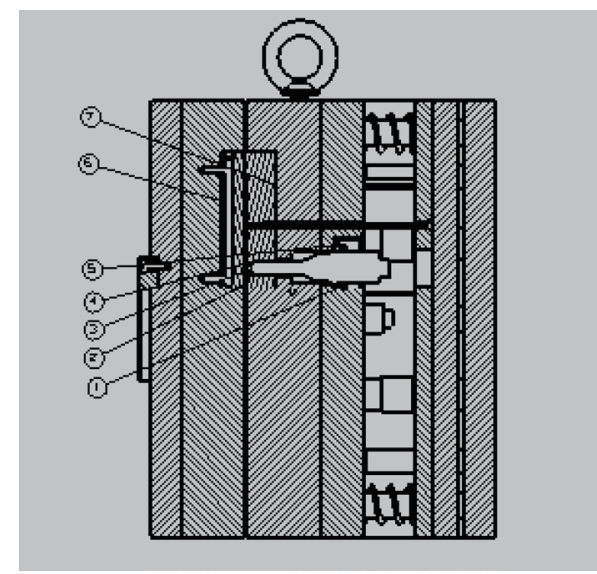

(a)

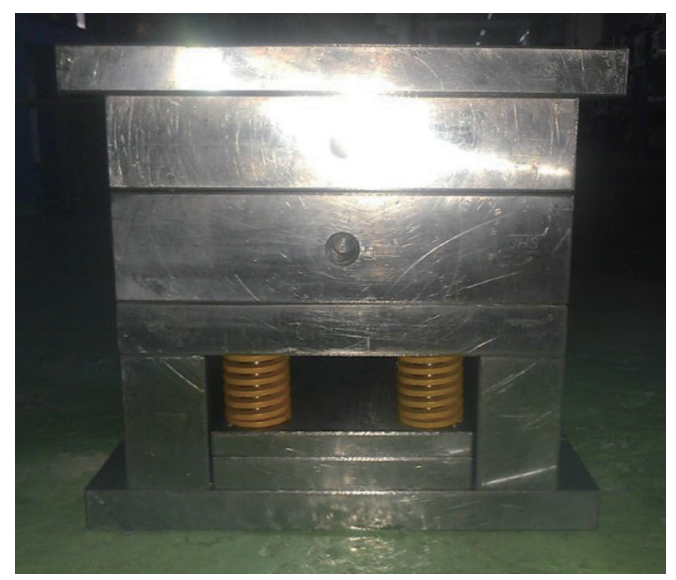

(b)

Fig. 20. (Color online) (a) Structural diagram of key parts of the mold (1, bolt; 2, cavity insert; 3, ultrasound vibrator; 4 , fluororubber ring; 5, clamping; 6, core; 7, cavity). (b) Ultrasonic injection mold-assisted thin wall. 


\section{Conclusions}

(1) On the basis of the characteristics of thin-wall injection molding technology and the principle of ultrasonic vibration, an ultrasonic-assisted system consisting of an ultrasonic generator, an ultrasonic horn, and an ultrasonic transducer was developed. The ultrasonic vibration was applied vertically in the direction of the polymer melt filling flow, and the end face of the ultrasonic vibrator was indirectly contact with the polymer melt in the cavity of the mold. Ultrasound is used to reduce the viscosity of the polymer melt and improve the internal microstructure so as to reduce warpage and improve the mechanical properties and the appearance quality of products.

(2) MOLDFLOW was used to simulate the injection molding of thin-wall microinjection parts to optimize the design of the gate, runner, primary runner, and cooling system. Through the analysis and numerical simulation of each parameter, the optimization scheme of the microinjection mold is put forward, which improves the accuracy and efficiency of the main system in mold designing. The ultrasonic system and thin-wall microinjection mold are combined to complete the ultrasonic-assisted thin-wall microinjection mold. The ultrasonic system was combined with the thin-wall microinjection mold and mold cavity pressure measurement system to complete the development of the ultrasonic-assisted thin-wall microinjection mold and the design of the mold cavity pressure measurement system, optimize process parameters, and improve the product quality.

\section{Acknowledgments}

This work is partially supported by the Natural Science Foundation of Fujian Province, China (2019J01709).

\section{References}

1 M. Rath, J. Döring, W. Stark, and G. Hinrichsen: NDT and E Int. 33 (2000) 123. https://doi.org/10.1016/S09638695(99)00029-8

2 V. Piotter, T. Hanemann, R. Ruprecht, and J. Haußelt: Microsys. Technol. 3 (1997) 129.

3 J. T. Huang and S. C. Cheng: Sens. Actuators, A 101 (2002) 269. https://doi.org/10.1016/S0924-4247(02)002170

4 B. Y. Jiang, J. L. Hu, J. Li, and X. C. Liu: J. Cent. South Univ. 19 (2012) 380. https://doi.org/10.1007/s11771012-1015-4

5 N. Zhang and M. D. Gilchrist: Polym. Test. 31 (2012) 748. https://doi.org/10.1016/j.polymertesting.2012.04.012

6 G. Francesco, C. Teresa, A. Giuseppina, and F. Luigino: Mater. Des. 60 (2014) 274. https://doi.org/10.1016/ j.matdes.2014.04.004

7 X. M. Jing, D. Chen, D. M. Fang, C. Huang, J. Q. Liu, and X. Chen: Microelectron. J. 38 (2006) 120. https:// doi.org/10.1016/j.mejo.2006.09.003

8 M. A. Usama, M. Silvia, and R. A. Jeffrey: Microfluid. Nanofluid. 7 (2001) 1613. https://doi.org/10.1007/ s10404-009-0421-X

9 L. Yu, L. J. Lee, and K. W. Koelling: Polym. Eng. Sci. 44 (2004) 1866. https://doi.org/10.1002/pen.20188

10 E. Amir, P. Selvan, C. Francisco, and W. Hao: Polym. Compos. 37 (2016) 213. https://doi.org/10.1002/pc.23172

11 H. Eghbal and B. S. Abu: Mater. Des. 44 (2012) 62. https://doi.org/10.1016/j.matdes.2012.04.058

12 C. Lu, X. F. Yu, and S. Y. Guo: Polym. Eng. Sci. 45 (2005) 1666. https://doi.org/10.1002/pen.20456

13 Y. Z. Yang, C. C. Huang, and J. Tao: J. Polym. Eng. 36 (2015) 113. https://doi.org/10.1515/polyeng-2015-0042 
14 D. Yang, P. Zhao, H. Zhou, and L. Chen: J. Reinf. Plast. Compos. 33 (2014) 1403. https://doi. org $/ 10.1177 / 0731684414535277$

15 C. M. Yen, J. C. Lin, W. J. Li, and M. F. Huang: J. Mater. Process. Technol. 178 (2006) 1. https://doi. org/10.1016/j.jmatprotec.2005.02.153

16 S. J. Liu and Y. C. Wu: Polym. Test. 26 (2007) 232. https://doi.org/10.1016/j.polymertesting.2006.10.008

17 W. M. Yang and H. Yokoi: Polym. Test. 22 (2003) 37.

18 L. Yu, C. G. Koh, L. J. Lee, K. W. Koelling and M. J. Madou: Polym. Eng. Sci. 42 (2004) 871. https://doi. org/10.1002/pen.10998

19 R. Ruprecht, T. Gietzelt, K. Müller, V. Piotter, and J. Haußelt: Microsyst. Technol. 8 (2002) 351. https://doi. org/10.1007/s00542-001-0153-7 